\title{
Damage to cerebellocortical pathways after closed head injury: a behavioural and magnetic resonance imaging study
}

\author{
Patrick Haggard, R Chris Miall, Derick Wade, Sue Fowler, Alex Richardson, Philip
} Anslow, John Stein

\begin{abstract}
The objective was to investigate the anatomical substrate of ataxia seen after severe head injury. Five patients were recruited from present and former inpatients at Rivermead Rehabilitation Centre. All patients had had a closed head injury and all had cerebellar type ataxia. Four normal controls were also studied. Brain MRI, clinical examination, computer based recording, and analysis of visuomotor tracking were carried out.

Focal damage was found in the superior cerebellar peduncle in all five ataxic patients. The patients' tracking movements showed profound tremor, and unusual reliance on visual feedback.

Ataxia seen after severe head injury can arise from damage to the superior cerebellar peduncle, which may interfere with the cerebellocortical circuits involved in coordinated movement.
\end{abstract}

(F Neurol Neurosurg Psychiatry 1995;58:433-438)

Keywords: magnetic resonance imaging; cerebellar ataxia; cerebellar peduncles; visuomotor tracking

Cerebellar ataxia is sometimes seen after severe closed head injury. A postmortem study in one case many years after injury showed focal damage to the superior cerebellar peduncle (SCP) after severe head injury, and a few neurosurgical cases of SCP damage in ataxic patients with head injury have also been reported. ${ }^{2}$ The SCP is anatomically vulnerable due to its exposed location in the roof of the fourth ventricle, and it carries all of the ascending output of the cerebellum to the red nucleus and contralateral motor cortical areas. The brain damage underlying ataxia in living patients, and the associated movement patterns have, however, not generally been related to measures of ataxia in sufficient detail to clarify the role of these cerebellocortical pathways in normal motor control. A recent study has established the role of MRI in investigating degenerative ataxias, ${ }^{3}$ but has focused on measures of the cerebellar cortex rather than the peduncles.

We therefore studied patients with pronounced ataxia after severe head injury, to investigate whether damage to the SCP could be shown by MRI, and to relate such damage to the patients' movement disorder.

\section{Methods}

Five patients were recruited from among the present and former inpatients at Rivermead Rehabilitation Centre. All had had a closed head injury, and all had cerebellar type ataxic signs (for example, kinetic tremor in fingernose pointing and intermittent smooth pursuit eye movements). Four normal controls, who were roughly age matched with the patients, were also studied. Local ethics committee approval was obtained. One further control subject performed visuomotor tracking, but was not scanned.

All patients were examined by a neurologist who confirmed cerebellar type ataxic signs. Formal measures included the Rivermead mobility index, ${ }^{4}$ the time taken to walk $10 \mathrm{~m},{ }^{5}$ the 10 hole peg test of manual dexterity, ${ }^{6}$ the short orientation memory-concentration test, ${ }^{7}$ a modified Wisconsin card sorting test, ${ }^{8}$ and verbal fluency (number of words over three one minute periods). ${ }^{9}$ Four of the five patients were examined by an orthoptist, who also recorded the patients' eye movements.

Visuomotor tracking was measured in patients and controls with standard procedures described elsewher ${ }^{10}$ : the subject rotates a lever by wrist flexion and extension through $45^{\circ}$, trying to superimpose a cursor spot on a target spot, moving at one of five constant velocities (11.25-21.33\%) across a visual display unit. The target spot moved through about $20^{\circ}$ of visual angle on each ramp. The experimenter verified that the subjects fixated the screen, and did not look at their moving hand. To investigate the relative importance of visual guidance and predictive control in patients and controls, we blanked out either the target or the cursor halfway through each ramp in some blocks of trials, asking the patient to continue tracking as accurately as possible. ${ }^{11}$ Tracking performance was measured by calculating the errors between the positions of the target and the patient's cursor, and between the velocities of target and cursor. Velocity errors are particularly sensitive to intermittency and tremor in tracking.

Patients and controls were scanned using axial and coronal slices in a T2 FSE sequence on a $1.5 \mathrm{~T}$ GE Signa MRI scanner. All scans were inspected and reported by a radiologist. Axial scans were taken parallel to the anterior commissure-posterior commissure line in each patient and control. Coronal scans were parallel to the scanner table. Axial 
Table 1 Clinical presentation and test scores for five patients with head injury

\begin{tabular}{|c|c|c|c|c|c|c|c|c|c|c|c|}
\hline \multirow[b]{2}{*}{ Patient } & \multirow[b]{2}{*}{ Sex } & \multirow[b]{2}{*}{ Age } & \multirow{2}{*}{$\begin{array}{l}\text { Years/ } \\
\text { months } \\
\text { since injury }\end{array}$} & \multicolumn{2}{|l|}{ Presentation } & \multicolumn{2}{|c|}{ Handedness } & \multicolumn{2}{|l|}{$10 H P T$} & \multirow{2}{*}{$\begin{array}{l}\text { Posture, gait } \\
\text { remarks }\end{array}$} & \multirow{2}{*}{$\begin{array}{l}\text { FAC } \\
\text { score }\end{array}$} \\
\hline & & & & Left arm & Right arm & Orig & Current & $L$ & $R$ & & \\
\hline 1 & $\mathbf{M}$ & 39 & $12 / 8$ & $\begin{array}{l}\text { Moderate } \\
\text { ataxia }\end{array}$ & Mild ataxia & $\mathbf{R}$ & Either & $2 \cdot 50$ & 1.73 & $\begin{array}{l}\text { Wide gait, } \\
\text { truncal tremor }\end{array}$ & 4 \\
\hline 2 & $\mathbf{M}$ & 21 & $2 / 6$ & $\begin{array}{l}\text { Moderate } \\
\text { ataxia }\end{array}$ & Mild ataxia & $\mathrm{L}$ & L & 2.05 & $3 \cdot 64$ & $\begin{array}{l}\text { Wide gait, mild } \\
\text { truncal tremor }\end{array}$ & 4 \\
\hline 3 & $\mathbf{M}$ & 30 & $4 / 6$ & Severe ataxia & $\begin{array}{l}\text { Very severe } \\
\text { ataxia }\end{array}$ & $\mathbf{R}$ & L & $4 \cdot 60$ & $5 \cdot 23$ & $\begin{array}{l}\text { Slight } \\
\text { titubation }\end{array}$ & 0 \\
\hline 4 & $\mathbf{F}$ & 28 & $3 / 0$ & $\begin{array}{l}\text { Very severe } \\
\text { ataxia,reduced } \\
\text { kinaesthesia }\end{array}$ & Severe ataxia & $\mathbf{R}$ & $\mathbf{R}$ & $14 \cdot 58$ & $4 \cdot 80$ & $\begin{array}{l}\text { Slight } \\
\text { titubation }\end{array}$ & 1 \\
\hline 5 & $\mathbf{M}$ & 38 & $14 / 6$ & $\begin{array}{l}\text { Spastic } \\
\text { hemiparesis }\end{array}$ & $\begin{array}{l}\text { Very severe } \\
\text { ataxia, } \\
\text { mild resting } \\
\text { tremor }\end{array}$ & $\mathbf{R}$ & $\mathbf{R}$ & $29 \cdot 70$ & $>79 \cdot 36^{\star}$ & $\begin{array}{l}\text { Moderate } \\
\text { titubation }\end{array}$ & 1 \\
\hline \multicolumn{2}{|c|}{$\begin{array}{l}\text { Published } \\
\text { norms }\end{array}$} & & & & & & & $\begin{array}{l}1.06 \\
(\text { SD } 0.093)\end{array}$ & 1.06 & & 4 \\
\hline
\end{tabular}

*The patient could not perform the test to criterion: if a score is also given, it is a hypothetical overall test score based on the time taken to perform some part of the test. The published norms indicate either the actual score of control subjects in published studies, or the score defined as normal in the test protocol; 10 hole peg test scores are given in seconds per peg correctly placed; verbal fluency is the total number of valid words generated in three minutes; modified Wisconsin card sorting test (MWCST) scores are given as categories achieved (cats). TE = total errors; \% PE = percentage of errors involving preserveration.

and coronal slices were $3 \mathrm{~mm}$ thick, without intervals. Quantitative measures obtained from the MRI included the volume of the cerebellum relative to the posterior fossa, the height of the fourth ventricle, and the area of a single slice through the cerebral cortex, at the level of the lateral ventricles, relative to the subdural area. We also measured the widths of the middle cerebellar peduncle and superior cerebellar peduncle in axial images. These correspond to the number of fibres entering the cerebellum in the corticocerebellar pathways and leaving in the cerebellocortical pathways.

\section{Results}

Table 1 summarises details of the patients and neurological measures. The patients varied considerably in the degree and distribution of their ataxia. Ataxia was typically bilateral, but the degree of ataxia, assessed by hypermetria and kinetic tremor in finger-nose pointing, was rarely equivalent in the two arms. Patient 5 had a left spastic hemiparesis, masking any possible ataxia on that side, and a slight resting tremor on the right side. Patient 2 had only mild ataxia in finger-nose pointing with the left hand, yet was still slower than normal subjects on the peg test. Patient 4 showed slight loss of cutaneous and joint position sense in her right arm, but the other patients' proprioception was normal on clinical tests. Motor power and muscle reflexes were relatively intact in the ataxic arms. All were dysarthric, but none was dysphasic. Although three patients were reported to have cognitive and behavioural abnormalities, all scored within normal limits on the short orientation memory-concentration test. One patient (4) scored slightly below normal on card sorting. Two verbal fluency scores were below average (patients 2 and 4), but still within normal limits.

Orthoptic examination and eye movement recording was performed in all patients except patient 5. The patients showed hypermetric saccades and jerky smooth pursuit in eye movement recording. Interestingly, all showed small square wave jerks during fixa- tion. All had reduced stereopsis. Patients 1, 3 , and 4 had diplopia.

Patients with unilateral ataxia performed visuomotor tracking with their ataxic arm, whereas the bilaterally ataxic patients tracked with the most ataxic arm that was still capable of holding and moving the joystick. Control subjects tracked with their preferred hand. Patients showed two different patterns of kinetic tremor in ramp tracking (fig 1).

Two patients ( 2 and 5 ) showed a continuous tremor at around $3 \mathrm{~Hz}$, in which the wrist oscillated, even reversing the direction of motion. The other patients made less frequent intermittent corrections, with fewer reversals of tracking direction. As a result, their cursor velocity oscillated around the target velocity, leading to high velocity errors (table 2). The dominant frequency of intermittency in these three patients was around 1 $\mathrm{Hz}$.

Suppression of the target spot led to smoother tracking in both patients and normal subjects. The mean tracking velocity after suppression of the target, however, remained close to the correct value. Thus target suppression had no significant effect on position errors, but absolute velocity errors were significantly lower, because of reduced tremor. Suppression of the cursor spot produced a similarly significant reduction in intermittency and kinetic tremor, as calculated by velocity errors. This is particularly clear for patients 2, 3, and 5 in the first suppressed portion of fig 2. Cursor suppression also caused mean tracking velocity to depart consistently from the target velocity, leading to a statistically significant increase in position errors during cursor suppression. This sustained change in tracking velocity can be clearly seen in patients 1,3 , and 4 in the second suppressed portion of fig 2 . Thus the patients produced a smoother track when their cursor was switched off, but they could not match their velocity to that of the visual target, and drifted gradually off target.

Initial inspection of the MR images showed pronounced atrophy of the cerebrum and cerebellum in the patients relative to the controls. The atrophy was accompanied by 


\begin{tabular}{cclllll}
\hline $\begin{array}{l}R M I \\
\text { Score }\end{array}$ & $\begin{array}{l}10 M T \\
(s)\end{array}$ & $\begin{array}{l}\text { SOMC } \\
(\%)\end{array}$ & $\begin{array}{l}\text { Verbal } \\
\text { fluency }\end{array}$ & $\begin{array}{l}\text { MWCST } \\
\text { Cats }\end{array}$ & $\begin{array}{l}\text { MWCST } \\
\text { TE }\end{array}$ & $\begin{array}{l}\text { MWCST } \\
\% P E\end{array}$ \\
\hline 14 & $9 \cdot 73$ & 28 & 32 & 5 & 11 & 9 \\
14 & $6 \cdot 04$ & 24 & 24 & 5 & 11 & 18 \\
12 & $64 \cdot 0$ & 26 & 29 & 6 & 1 & 0 \\
6 & $770 \cdot 0^{\star}$ & 24 & 22 & 6 & 6 & 33 \\
9 & $\star$ & 24 & 36 & 6 & 10 & 10 \\
\hline
\end{tabular}

in three of the five patients (3, 4, and 5). Unilateral focal damage to the cerebral peduncles on the same side was seen in two of these patients ( 3 and 4). Patient 2 showed evidence consistent with an old haemorrhagic contusion in the inferior aspect of the left temporal lobe.

Quantitative measures of cerebellar and cortical atrophy were made interactively by computer. Figure 3 shows threshold coronal sections through the cerebellar cortex in a typical patient and a control.

Differences in degree of atrophy between the two sides of the cerebrum or cerebellum were negligible, so combined bilateral measures were used for statistical analysis. Table 2 shows the results. Because of natural intersubject variability in the size of cerebellum, we performed statistical tests on the ratio of the cerebellar volume to the entire outline of the posterior fossa, and on the ratio of the area of cerebrum to the entire subdural area in a single axial slice at the level of the lateral ventricles. Multivariate analysis of variance (MANOVA) ${ }^{12}$ of the cerebellar and cerebral ratios showed a significant difference between

Figure 1 Typical samples of visuomotor tracking in a control subject and in each patient (1-5). The target waveform is shown as a series of ramps. Note the intermittent tracking in patients 4, 1, and 3, and the higher frequency kinetic tremor, with more reversals of movement direction, in patients 2 and 5 . ventriculomegaly. The patients with the greatest degree of atrophy $(1,5)$ had the greatest elapsed time since the initial injury. As well as atrophy, all scans were inspected by a neuroradiologist for focal pathology. Unilateral focal damage to the SCP was seen
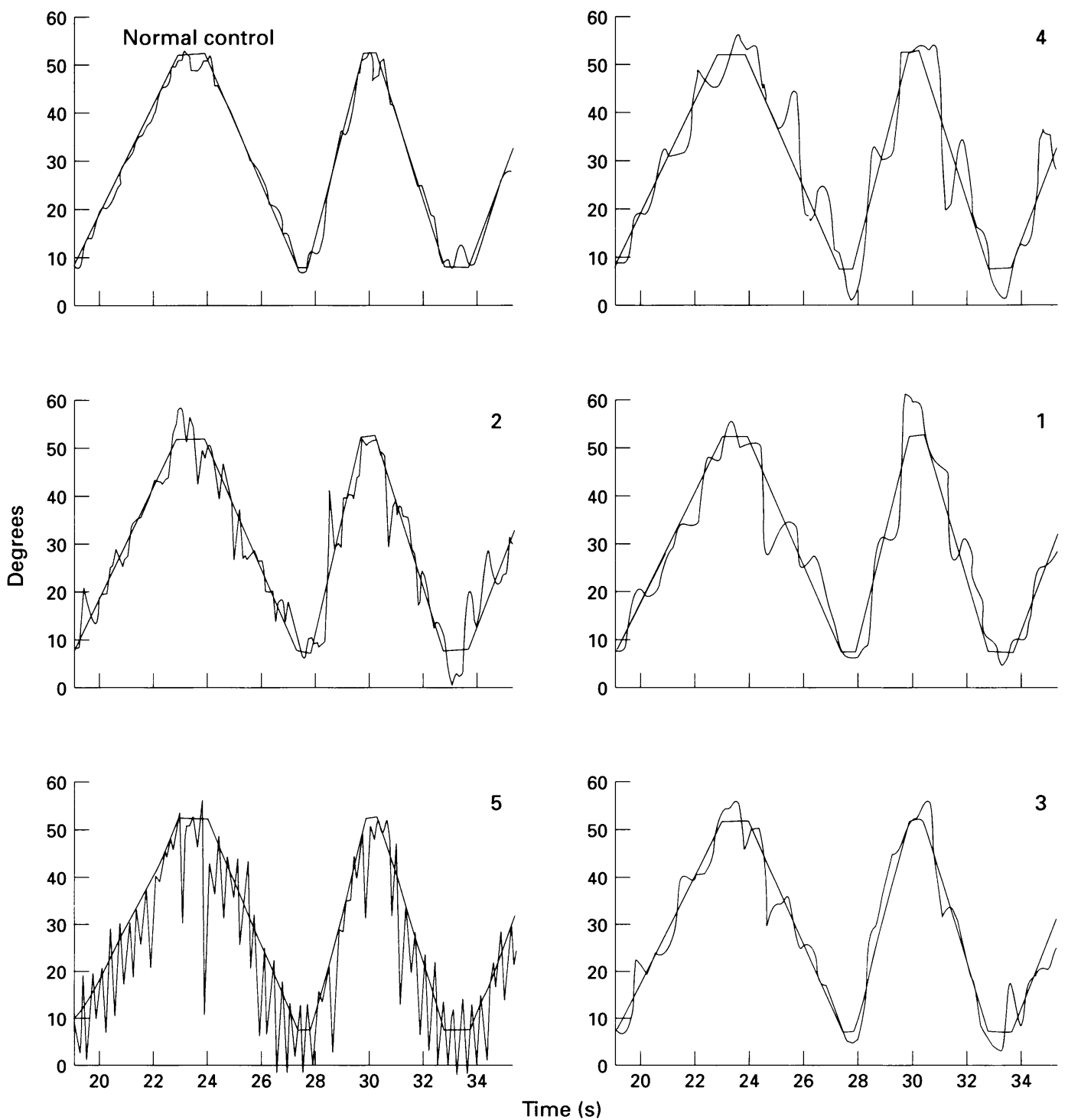
Table 2 Visuomotor tracking performance scores

\begin{tabular}{|c|c|c|c|c|c|c|c|c|c|c|}
\hline & \multirow{2}{*}{\multicolumn{2}{|c|}{ Mean tracking errors }} & \multirow{3}{*}{$\begin{array}{l}\text { Path } \\
\text { length }\end{array}$} & \multirow{2}{*}{\multicolumn{3}{|c|}{ Residual Power }} & \multicolumn{4}{|c|}{ Normal v suppressed errors } \\
\hline & & & & & & & \multicolumn{2}{|c|}{ Abs positional error } & \multicolumn{2}{|c|}{ Abs velocity error } \\
\hline & Position & Velocity & & $0-2 \mathrm{~Hz}$ & $2-4 \mathrm{~Hz}$ & 4-6 Hz & Target & Cursor & Target & Cursor \\
\hline \multicolumn{11}{|l|}{ Patients: } \\
\hline 1 & 201 & 935 & $1 \cdot 339$ & $127 \cdot 2$ & $34 \cdot 6$ & $6 \cdot 6$ & $437: 417$ & $388: 554$ & $1924: 106$ & $1780: 936$ \\
\hline 2 & 142 & 1404 & $2 \cdot 258$ & $149 \cdot 5$ & $217 \cdot 2$ & $34 \cdot 7$ & $231: 256$ & $156: 294$ & 2096:102 & $2304: 102$ \\
\hline 3 & 196 & 941 & 1.489 & $161 \cdot 3$ & $46 \cdot 4$ & $9 \cdot 0$ & $287: 319$ & $315: 322$ & $1318: 825$ & $1392: 861$ \\
\hline 4 & 260 & 1152 & $1 \cdot 780$ & $235 \cdot 3$ & $45 \cdot 6$ & $6 \cdot 3$ & $474: 329$ & $524: 572$ & $2130: 858$ & 2235:106 \\
\hline & 370 & 5055 & $7 \cdot 697$ & 223.9 & $3499 \cdot 0$ & $215 \cdot 6$ & $604: 884$ & 691:974 & $8601: 766$ & 9378:880 \\
\hline Mean $(n=5)$ & $233 \cdot 8$ & $1897 \cdot 4$ & $2 \cdot 913$ & $179 \cdot 4$ & $768 \cdot 6$ & $54 \cdot 4$ & 407:441 & $415: 543^{\star}$ & $3214: 229^{\star \star}$ & $3418: 253^{\star \star}$ \\
\hline \multicolumn{11}{|l|}{ Controls: } \\
\hline C1 & 65 & 434 & $1 \cdot 101$ & $11 \cdot 2$ & $5 \cdot 0$ & $3 \cdot 3$ & 113:252 & $101: 232$ & $674: 665$ & $694: 647$ \\
\hline $\mathrm{C} 2$ & 47 & 360 & 1.074 & $25 \cdot 5$ & $14 \cdot 6$ & 3.0 & $67: 116$ & $54: 197$ & 493:398 & $464: 405$ \\
\hline C3 & 67 & 427 & 1.068 & $8 \cdot 3$ & $7 \cdot 7$ & $4 \cdot 3$ & $124: 170$ & $103: 124$ & $625: 477$ & $645: 410$ \\
\hline C4 & 51 & 345 & 1.073 & $5 \cdot 5$ & $3 \cdot 2$ & $2 \cdot 2$ & $90: 154$ & $82: 203$ & $530: 405$ & 488:469 \\
\hline C5 & 84 & 566 & $1 \cdot 240$ & $39 \cdot 9$ & $23 \cdot 7$ & $11 \cdot 8$ & $177: 184$ & $168: 163$ & $957: 528$ & $527: 499$ \\
\hline Mean $(n=5)$ & $62 \cdot 8$ & $426 \cdot 4$ & $1 \cdot 111$ & $18 \cdot 1$ & $10 \cdot 8$ & $4 \cdot 9$ & $114: 175^{\star}$ & $102: 184$ & $656: 495$ & $564: 486$ \\
\hline
\end{tabular}

Path length is the mean distance travelled compared with perfect tracking; residual power is the power in the frequency spectrum of tracking velocity minus the target contribution; normal $v$ suppressed errors are the mean errors over corresponding tracking segments in trials with full display $v$ trials in which either the target or the cursor was suppressed.

${ }^{\star} \mathrm{P}<0.05 ;{ }^{\star \star P}<0.01$ ( $t$ test), $\mathrm{df}=4$ ).

patients and controls $(F(2,6)=34 \cdot 04, P=$ $0.0006)$. Standardised canonical coefficients (SCCs) showed a $61 \%$ greater contribution of cerebellum score (SCC $=2 \cdot 069$ ) than of cerebrum ( $\mathrm{SCC}=1 \cdot 2820$ ) to the intergroup difference. That is, the atrophy is more pronounced in the cerebellum than in the cerebrum.

Figure 4 shows enlarged portions of axial slices containing the SCP and MCP in typical patients and controls, together with width markings. Table 3 shows individual widths, together with the number of slices used for each measurement. The MCP was somewhat smaller in the patients, averaging $74 \%$ of its width in controls. The SCP was greatly damaged, however, reaching only $40 \%$ of its control width. The images in fig 4 show those slices that scored closest to the mean value for each measurement. A MANOVA of the MCP and SCP widths showed a significant difference between patients and controls
$(\mathrm{F}(2,6)=24.0289, \mathrm{P}=0.0014)$. The SCCs showed a $155 \%$ greater contribution of the SCP (SCC $=2.073$ ) than of the MCP (SCC $=0.812$ ) to the intergroup difference, indicating disproportionate damage to the SCP.

Taken together, our MRI measures indicate that damage was more pronounced in the cerebellum than in the rest of the cerebrum, and was much greater in the SCP than in the MCP. We are not aware of any neurologically relevant history in the patients, other than head injury, which could explain these findings. Further, none of the patients had any substantive abnormal history of drug or alcohol misuse, or any other factor likely to cause cerebellar atrophy. Thus although the effects of severe head injury are normally quite diffuse, we have been able to show specific focal effects in the cerebellum and in the cerebellocortical pathway in patients with ataxia.

By contrast with the cerebellar volumes,
Figure 2 Effects of cursor suppression on patients' tracking. The upper trace shows the target waveform, corresponding to $45^{\circ}$ of wrist rotation. During the periods marked by the black bar (cursor off), the spot corresponding to wrist position was suppressed. Typical samples from each of the five patients show reduced intermittency and tremor during these periods. Note also the gradual drift off target (for example, by patients 3, 4, and 5 and in the second suppressed period) due to failure to match movement velocity to target velocity.

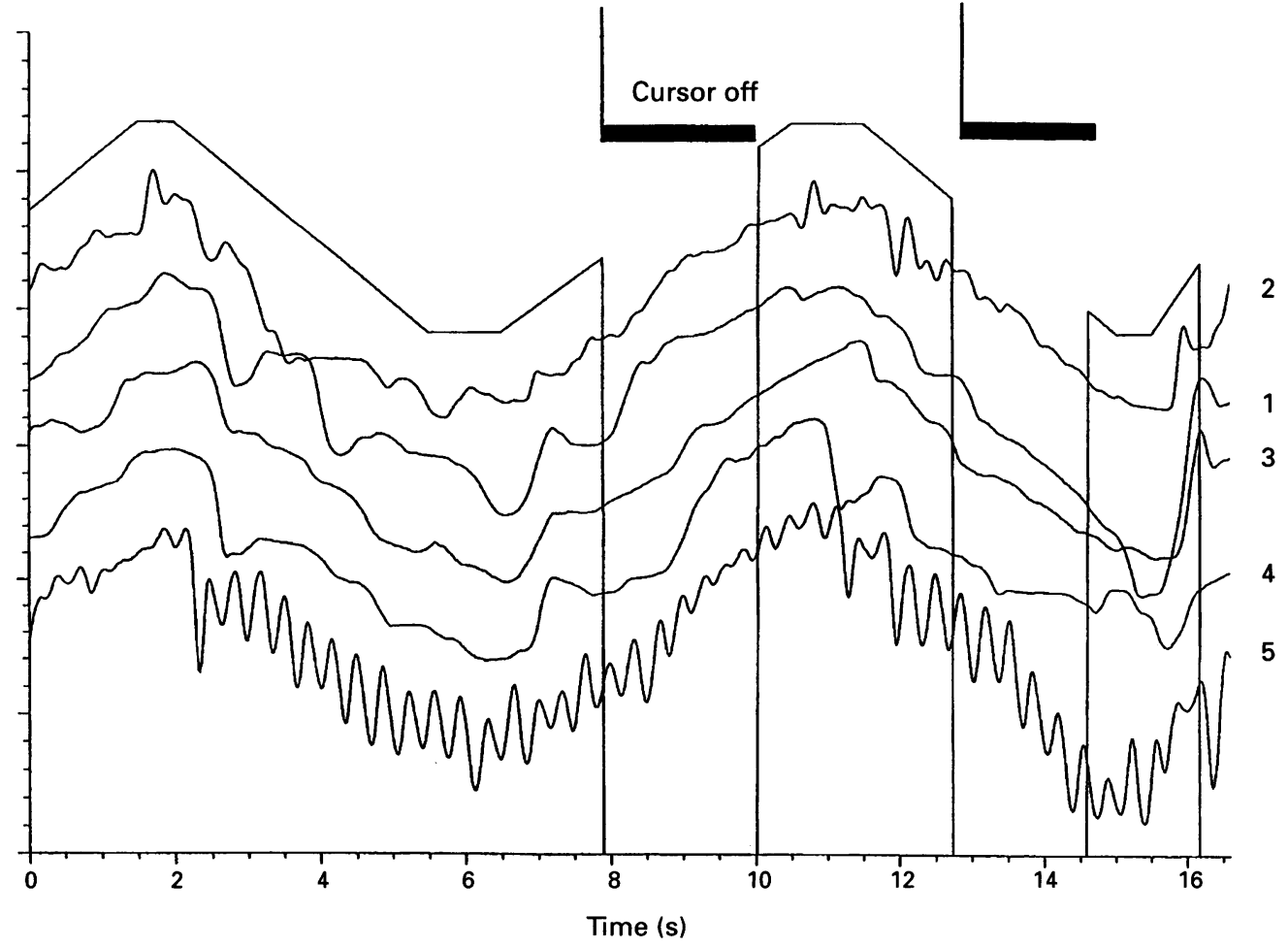


Figure 3 Threshold coronal slices outlining the cerebellar cortex in coronal slices in a typical patient and a typical control. Slices are $3 \mathrm{~mm}$ thick, and are oriented parallel to the scanner table. Note the shrinkage of the cerebellar folia in the patient, including the inferior vermis.

Figure 4 Axial slices through the middle cerebellar peduncle (MCP) and superior cerebellar peduncle (SCP) in typical patients and controls.

Slices are $3 \mathrm{~mm}$ thick, and parallel to the anterior commissure-posterior commissure line in each case. CSF shows as white. The white bar on each lefi peduncle shows the peduncle width on that slice, as measured interactively by computer. Scale bars on each image give $1 \mathrm{~cm}$ intervals. Note the disproportionately thin $S C P$ in the patient.

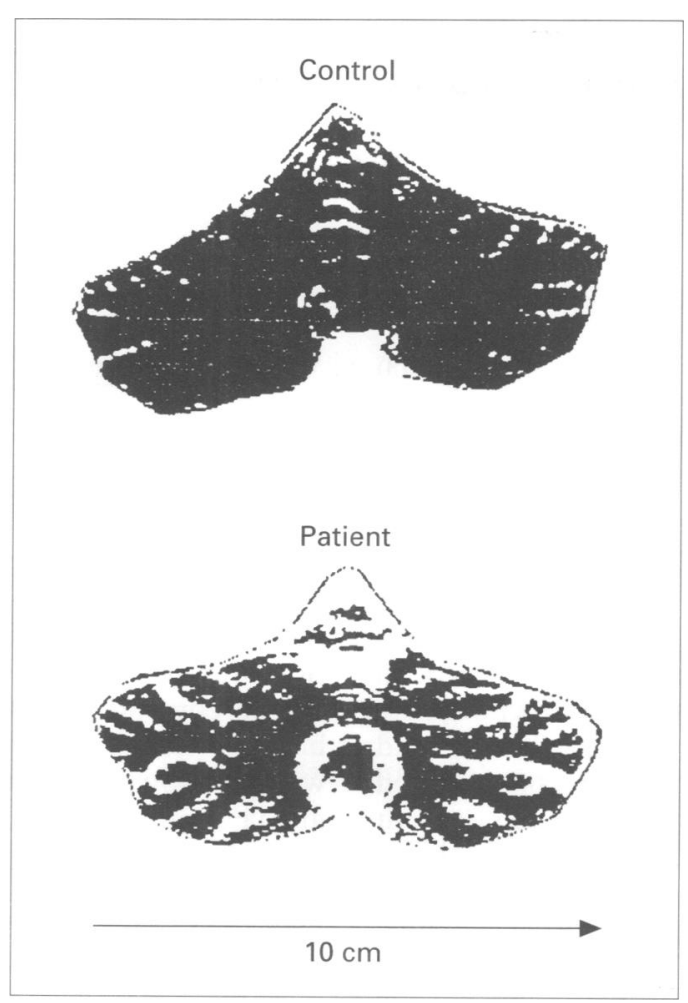

the widths of the MCP and SCP often differed substantially between the left and right sides. We therefore used Spearman's rank correlation to relate the patients' visuomotor tracking performance, taken from table 2, with the ipsilateral peduncle width. We found poor correlations between position and velocity errors in tracking with full visual guidance and SCP width. The effects of cursor and target suppression, taken as the ratio of normal to suppressed tracking errors, correlated better with SCP width for velocity errors $(-0.949, P=0.051$ for target suppression; $-0.734, P=0.262$ for cursor suppression) than for positional errors $(-0.211, P=0.789$ for target suppression; $0.211, P=0.789$ for cursor suppression). The correlations with velocity measures suggest that greater damage to the corticocerebellar pathway leads to more intermittent and tremulous movement, perhaps because of an increasing need to rely on delayed visual feedback for detecting and correcting movement errors. These trends must be treated cautiously, because the number of patients is small, but they suggest a specific role of the corticocerebellar pathway in regulating movement velocity.
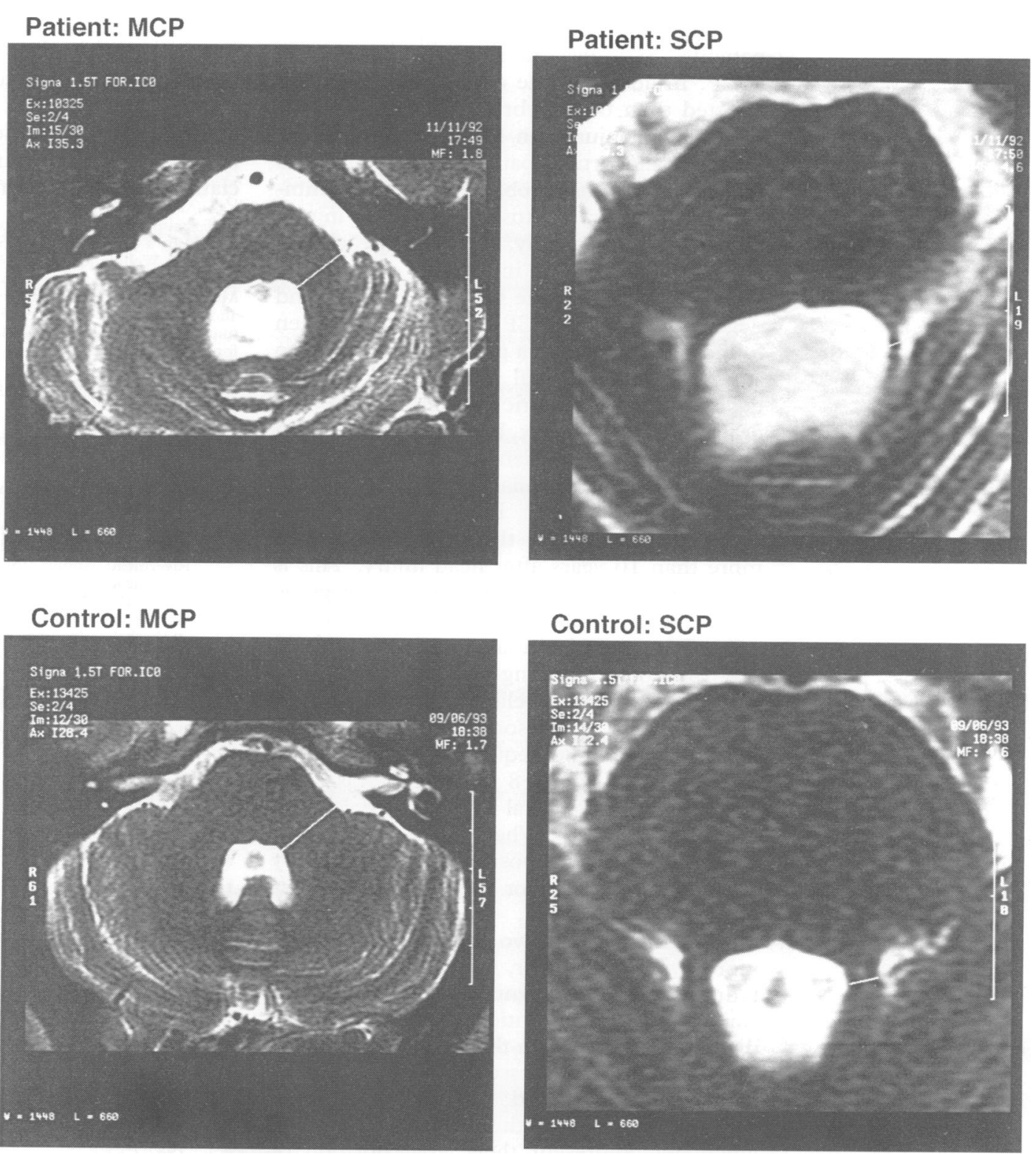
Table 3 MRI measures for patients and controls

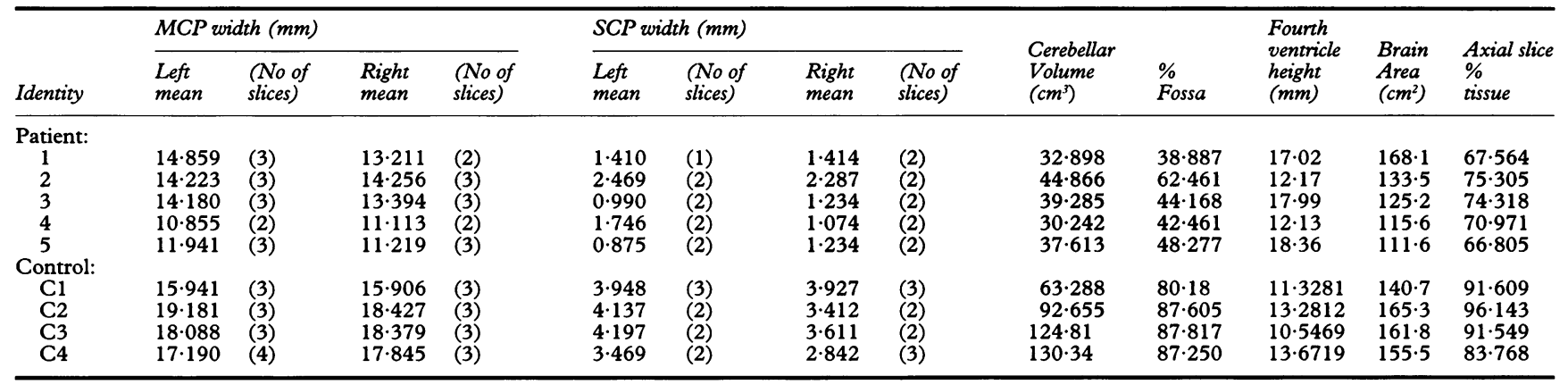

\section{Discussion}

We have found specific damage to the cerebellocortical pathway in the superior cerebellar peduncle in five ataxic patients with head injury. The SCP seems to be more vulnerable than the MCP because of its smaller size and exposed situation. This study concentrated on patients selected by virtue of their evident long lasting ataxia and ability to cooperate. Consequently it cannot rule out the possibility that the SCP is damaged in other patients, who are not ataxic.

Statistical comparison between normal subjects and controls showed that the patients' SCP was more affected than the MCP. In addition, the cerebellum was more affected than the cerebrum. This shows that severe head injury can have focal effects on the cerebellocortical pathway. Our measures of peduncle width probably reflect a combination of primary contusion with shear injury, and secondary atrophy. Although we cannot be certain that shear injury has occurred in these patients, we note that focal lesions and degeneration of the SCP have previously been found postmortem in a group of patients who survived diffuse axonal injury for at least 60 days. ${ }^{1314}$ Our volumetric measures of the folia of the cerebellar cortex, however, showed secondary atrophy in patients with SCP damage, even when the cerebellar input via the MCP was relatively spared. Further, the atrophy was most obvious in the two patients seen more than 10 years after head injury. This is consistent with a mechanism of retrograde degeneration, possibly due to the inability of the cerebellum to send normal output to the cortex.

Visuomotor tracking data showed that damage to the cerebellocortical pathway in these patients was associated with profound kinetic tremor. The frequency of their tremor, which ranged from 0.8 to $1.5 \mathrm{~Hz}$, was commensurate with visual feedback delays in visuomotor tasks. ${ }^{10}$ When visual feedback of the patients' current position was removed by suppressing the cursor or target spot, this tremor was reduced, producing smoother movements. In the two patients with faster, more violent tremor, cursor suppression reduced the tremor significantly without abolishing it entirely. Patients also tended to diverge gradually from the correct track when the cursor was suppressed, but not when the target was suppressed. This gradual divergence suggests that the patients could not adequately represent their wrist position or velocity in the absence of visual feedback. These results suggest that the intact SCP carries a predictive representation of limb position and velocity, which is necessary for fine motor control. The finding that all patients had abnormal eye movements is consistent with previous observations that patients with ataxia seen soon after injury have a worse prognosis for recovery if abnormal eye movements are present. ${ }^{15}$ This would suggest that persistent ataxia, as seen in these five patients, is associated with more extensive local brain stem damage.

Further studies are needed to investigate this relation in more detail. At present we can conclude that the presence of ataxia long after severe head injury is often associated with damage to the superior cerebellar peduncle; but the strength and importance of this association needs further investigation.

P H is supported by a Wellcome Trust Research Fellowship, R C M by a Wellcome Trust Senior Research Fellowship, and A R by a Wellcome Trust Programme grant. We are grateful to REMEDI, to Oxfordshire Health Authority, to the McDonnell-Pew Research Centre in Cognitive Neuroscience, and to the MRC Brain and Behaviour Centre for additional funding. We are grateful to the patients and normal subjects for their cooperation.

1 Chester CS, Reznick BR. Ataxia after severe head injury: the pathological substrate. Ann Neurol 1987;22:79-84.

2 Richardson RR. Rehabilitative neurosurgery: posttraumatic syndrome. Stereotact Funct Neurosurg 1989;53. 105-12.

3 Ormerod IEC, Harding AE, Miller DH, et al. Magnetic resonance imaging in degenerative ataxic disorders. Neurol Neurosurg Psychiatry 1994;57:51-7.

4 Collen FM, Wade DT, Robb GF, Bradshaw CM. The Rivermead Mobility Index: a further development of the Rivermead Motor Assessment. International Disability Studies 1991;13:50-4

5 Collen FM, Wade DT, Bradshaw CM. Mobility after stroke: reliability of measures of impairment and disabilstroke: reliability of measures of impairment and

6 Annett M. Measurement of laterality. In: Crawford JR Parker DM, Mackinlay WW, eds. A handbook of neuropsychological assessment. Hove: LEA, 1992.

7 Katzman R, Brown T, Fuld P, Peck A, Schechter R, Schimmel H. Validation of a short orientation-memoryconcentration test of cognitive impairment. $A m$ Psychiatry 1983;140:734-9.

8 Nelson HE. A modified card sorting test sensitive to frontal lobe defects. Cortex 1976;12:313-24.

9 Miller E. Verbal fluency as a function of a measure of verbal intelligence and in relation to different types of cerebral pathology. Br f Clin Psychol 23:53-7.

10 Miall RC, Weir DJ, Stein JF. Intermittent responses in human manual tracking. 7 Motor Behav 1993;25:53-63.

11 Beppu $H$, Suda $M$, Tanaka R. Analysis of cerebellar motor disorders by visually guided elbow tracking movement. Brain 1984;107:787-809.

12 Krzanowski WJ. Principles of multivariate analysis: a user's perspective. Oxford: Oxford University Press, 1988.

13 Hume Adams J, Mitchell DE, Graham DI, Doyle D. Diffuse brain damage of immediate impact type. Brain Diffuse brain dama.

14 Hume Adams J, Graham DI, Murray LS, Scott G. Diffuse axonal injury due to nonmissile head injury in humans: axonal injury due to nonmissile head injury in hum

15 Kotsoris HO, Volpe BT. Clinical characteristics of the late recovery from posttraumatic gait ataxia. $\mathcal{F}$ Neuro Rehab 1987;2:73-8. 